\title{
Opportunities and Limits of the Use of Azides in Industrial Production. Implementation of Safety Measures
}

\author{
Jean-Pierre Hagenbuch*
}

\begin{abstract}
Azides are very versatile precursors of organic synthesis functionalities such as amines, isocyanates, sulfonamides, triazoles, tetrazoles, triazolines, aziridines, amino acids and diazo compounds. In industry, one of the favourite starting materials for these syntheses is sodium azide which can generate hydrazoic acid whose toxicity and detonation potential is of major safety concern. However sodium azide is used daily in large tonnage in the air-bags of vehicles, in biologic institutes as a bactericide and in agriculture as a herbicide. In industrial synthesis, sodium azide is actually the starting material of herbicides, anti-HIV pharmaceuticals, anti-pain compounds and hypo tensors. This massive use of sodium azide represents severe toxicological and physical damage risks. The industrial synthesis under the scope of this presentation will be the manufacture of a tetrazole produced in several tens of tons per year. A risk assessment concluded that it would be necessary to conduct the reaction in a 'Bunker' and to minimise risks by absolutely avoiding generation of hydrazoic acid. This can be achieved by a careful design of the process and by strict organisational measures. Furthermore, the reaction equipment was designed to prevent any condensation of hydrazoic acid. One way to prevent its formation is to maintain the reaction medium under basic conditions at all times. This is achieved by using triethylamine hydrochloride as a buffer. In the applied reaction conditions it could be demonstrated that triethylamine was the refluxing compound at $130^{\circ} \mathrm{C}$ and that a thermally stable triethyl ammonium azide was formed. The environmental problem could be resolved by incineration of the wastewaters. In conclusion, reactions with sodium azide are safe, they only need a stabilising agent. A search for such compounds could be an interesting but rather dangerous research project.
\end{abstract}

Keywords: Azides · Production · Safety · Tetrazoles · Triethylamine

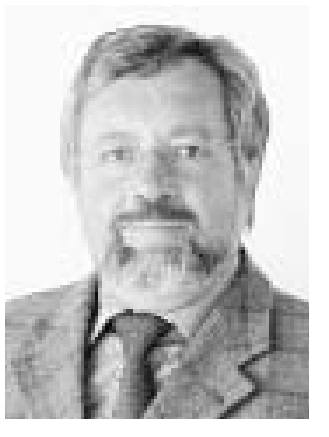

${ }^{\star}$ Correspondence: J.-P. Hagenbuch Orgamol SA

Production department

$\mathrm{CH}-1902$ Evionnaz

Tel.: +4127 7661322

Fax: +4127 7661481

E-Mail: jean-pierre_hagenbuch@orgamol.com www.orgamol.com
1. Use of Azides in Organic Synthesis (Scheme 1, a-m)

\subsection{Synthesis of Amines}

Azides are widely used in organic synthesis. Their first important usage is the synthesis of amines from alkyl halides [1]. A common process is the reaction of sodium azide with halides in polar organic solvents like dimethylformamide followed by catalytic hydrogenation or reduction with lithium aluminum hydride [2] or triphenylphosphine (Staudinger reaction) (a) [3].

Aromatic compounds can be directly aminated using trimethylsilyl azide and triflic acid as catalyst (b) [4].

In aminoglycoside syntheses, azides have been valuable as amine protecting groups allowing recovery of the original functionality with retention of configuration. The same procedure was used to produce amino acids (c) [5].

\subsection{Synthesis of Isocyanates}

Like alkyl halides, acyl halides are easily transformed to acyl azides which generate isocyanates after Curtius rearrangement (d) [6]. A similar procedure transforming directly a carboxylic acid to the amine in acidic conditions is named the Schmidt rearrangement.

\subsection{Synthesis of Sulfonamides}

In the same way sulfonyl halides yield sulfonamides after reduction either by sodium hydride or by photolytic reaction in isopropanol (e) [7].

\subsection{Synthesis of Triazoline}

Azides add to double bonds to give triazolines (f) [8].

\subsection{Synthesis of Aziridines}

Photolytic or thermal treatment of triazolines gives aziridines (g) [8]. 


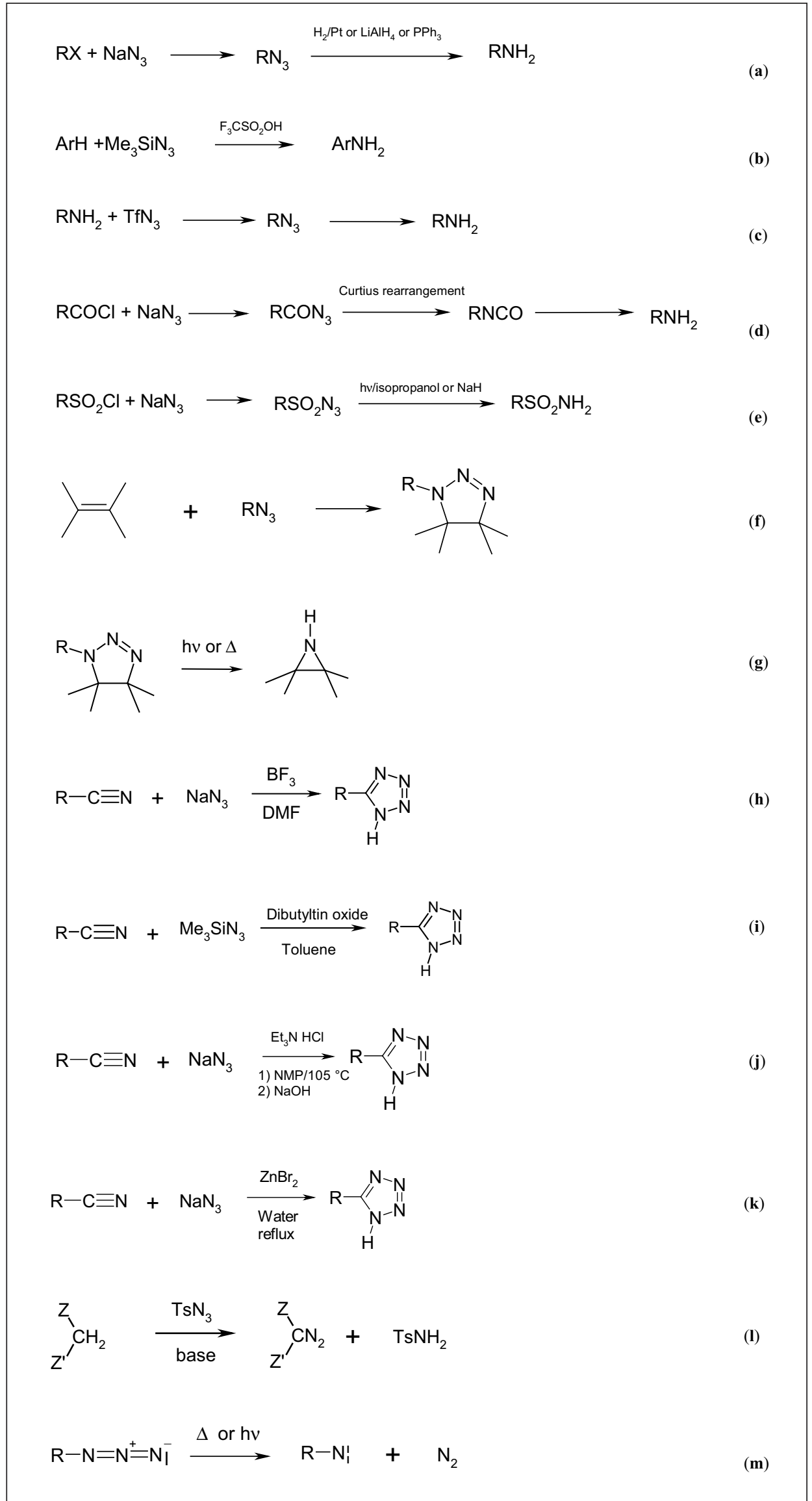

Scheme 1

\subsection{Synthesis of Tetrazoles}

An increasing importance of azides has appeared in the preparation of tetrazoles. There are many methods to perform this transformation: using strong Lewis acids (h) [9], tin or silicon azides (i) [10], ammonium azides (j) [11], and more recently using zinc salts in water (k) [12]. The latest method is claimed to be the safest and the best for the environment.

\subsection{Synthesis of Reactive Intermediates}

Other useful applications of azides are the formation of diazo-compounds (l) [13] or nitrenes (m) [14].

\section{Industrial Uses of Azides}

One of the most widely used starting materials is sodium azide, which is the inflating agent in the air-bags of vehicles [15]. It is also used as a chemical preservative in hospitals and laboratories, as pest control and herbicide or as soil sterilizing agent in agriculture [16].

Many active compounds are industrially produced from azides e.g. the herbicide Fentrazamide [17], the anti-pain compound Alfentanil [18], hypotensors Losartan [19] and Irbesartan [20], and the anti-HIV drug AZT [21].

\section{Sodium Azide as Starting Material}

\subsection{Production of Sodium Azide}

The production of such large quantities of sodium azide and the highly explosive nature of the substance requires the knowhow of specialized companies like Innochem, Dynamit Nobel or ICI Explosifs Inc.

The industrial processes do not seem straightforward if we look, for example, at that given by ICI: the reaction of ammonia gas on fused sodium followed by treatment with nitrous oxide [22].

\subsection{Properties of Sodium Azide}

Sodium azide is a crystalline white powder which decomposes at about $275^{\circ} \mathrm{C}$. It dissolves in water giving a basic solution ( $\mathrm{pH}>9$ ). On contact with acids, it liberates the highly toxic and detonating (at a simple vibration) hydrazoic acid. Although the latter is about 7 times less toxic (intraperitoneal LD50: $22 \mathrm{mg} / \mathrm{kg}$ ) than hydrogen cyanide $(2.99 \mathrm{mg} / \mathrm{kg})$ its maximal value of exposition (VME) was set 100 times lower $(0.1 \mathrm{mg} / \mathrm{kg})$ than that of HCN $(10$ $\mathrm{mg} / \mathrm{kg}$ ). It is harmless in diluted solutions 
but reacts with any part of the installation bearing $\mathrm{Pb}, \mathrm{Cu}, \mathrm{Hg}$, $\mathrm{Zn}$, concentrating explosive compounds. The boiling point of hydrazoic acid is $35^{\circ} \mathrm{C}$ at normal pressure and its decomposition enthalpy $(-6900$ $\mathrm{kj} / \mathrm{kg}$ ) is higher than that of trinitrotoluene (TNT, $-4700 \mathrm{kj} / \mathrm{kg}$ ). Sodium azide should not be used in halogenated solvents since it produces highly explosive azido compounds [23].

\section{Production of a Tetrazole}

\subsection{Reaction}

The industrial synthesis under the scope of this presentation is the manufacture of a tetrazole produced in several tens of tons per year (Scheme 2).

\subsection{Risk Assessment}

\subsubsection{Reaction Parameters}

From the risk assessment initiated at the start of the project, some important results appeared. The retained procedure is what is normally avoided in production: a batch type reaction where all ingredients are introduced at once and heated to a small reflux at $105{ }^{\circ} \mathrm{C}$ according a temperature ramp. However this procedure is acceptable because the reaction enthalpy is low. The reaction mixture decomposes at $150{ }^{\circ} \mathrm{C}$ with a $\Delta \mathrm{H}$ of about $-200 \mathrm{~kJ} / \mathrm{kg}$. Therefore, the temperatures must be well controlled.

Of course, the greater risk is the use of sodium azide giving, under acidic conditions, hydrazoic acid, a detonating liquid like nitro-glycerine. The distillation temperature of $\mathrm{HN}_{3}$ being $35^{\circ} \mathrm{C}$, accumulation of product in any part of the distilling device must be avoided. Similarly explosive metal azides should not be formed in any part of the installation, including the drainage system.

\subsubsection{Need for a Bunker}

If the whole quantity of sodium azide used in one batch is transformed to hydrazoic acid, there will be the equivalent of $120 \mathrm{~kg}$ of TNT formed. No wall is strong enough to support the explosion of such a quantity of product. However, according to the risk assessment of our customer it was decided to run the reaction in a bunker assuming that only a small quantity of hydrazoic acid (less than $1 \mathrm{~kg}$ ) could accumulate under deviate conditions. The bunker was also important to confine the use of sodium azide to a defined area.

\subsubsection{Transporting, Storing, Loading, and Disposing of $\mathrm{NaN}_{3}$}

Sodium azide is delivered in double plastic bags inside metallic $25-\mathrm{kg}$ drums.

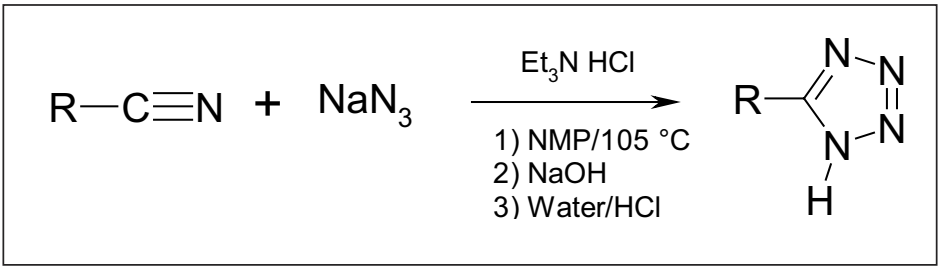

Scheme 2
Storage is allowed in a dedicated closed room equipped with fire detection and dry

In order to avoid spoilage, the reaction size was adapted to use a whole number of drums. Those are opened inside the bunker, which also contains a retention basin. Operators wear dedicated disposable equipment. Any material is cleaned before leaving the bunker and the clothes are packed in fiber drums for incineration. No unnecessary pipes enter the bunker and acidic media are excluded.

Any wastewater and organic effluents from the reaction are loaded in rail tank wagons for incineration.

\subsection{Design of the Plant}

4.3.1. Flux Diagram, Procedure, and Reactor

The basic concept was to run the azide reaction inside the bunker and then to transfer the reaction mixture on $30 \%$ sodium hydroxide to the adjacent plant using double jacket pipes and a reactor with a retention basin (Fig. 1).

The formation of explosive metal comlined reactors, Teflon pipes and anti-acid equipment (Fig. 2). To prevent any accumulation of hydrazoic acid, the distillation column was constructed as a simple tube bearing, on the top, a crown of nitrogen. A extinguishing media. pounds was prevented by the use of glass- dedicated absorber was constructed to collect the gases without creating vacuum inside the reactor.

After loading N-methyl pyrrolidone (NMP) and triethylamine. $\mathrm{HCl}$, an inprocess control (IPC) was introduced to assure that the mixture is not acidic by mistake $(\mathrm{pH}>6.8)$ before loading sodium azide. Then the operators have to clean the room, collect the disposable clothes in fiber drums and close the bunker. Using an automatic program, the reaction is heated to a moderate reflux that is observed with a camera. At least one operator has to be present during this phase. Alarm and automatic cooling systems are auctioned when gauges placed inside the reaction mixture, at the bottom and on top of the column, reach the predefined limits. Additionally, agitation failure is under the same control.

When the reaction is finished, the reactor located in the plant is filled with sodium hydroxide $30 \%$ and, to test that this substance really was introduced, an additional IPC $(\mathrm{pH}>12)$ is performed. The organic layer is then extracted with sodium hydroxide in order to remove any sodium azide. The aqueous phase is stored in a rail tank wagon for incineration. An IPC is performed to insure that no sodium azide remains in the organic phase before extracting with water and precipitating with hydrochloric acid.

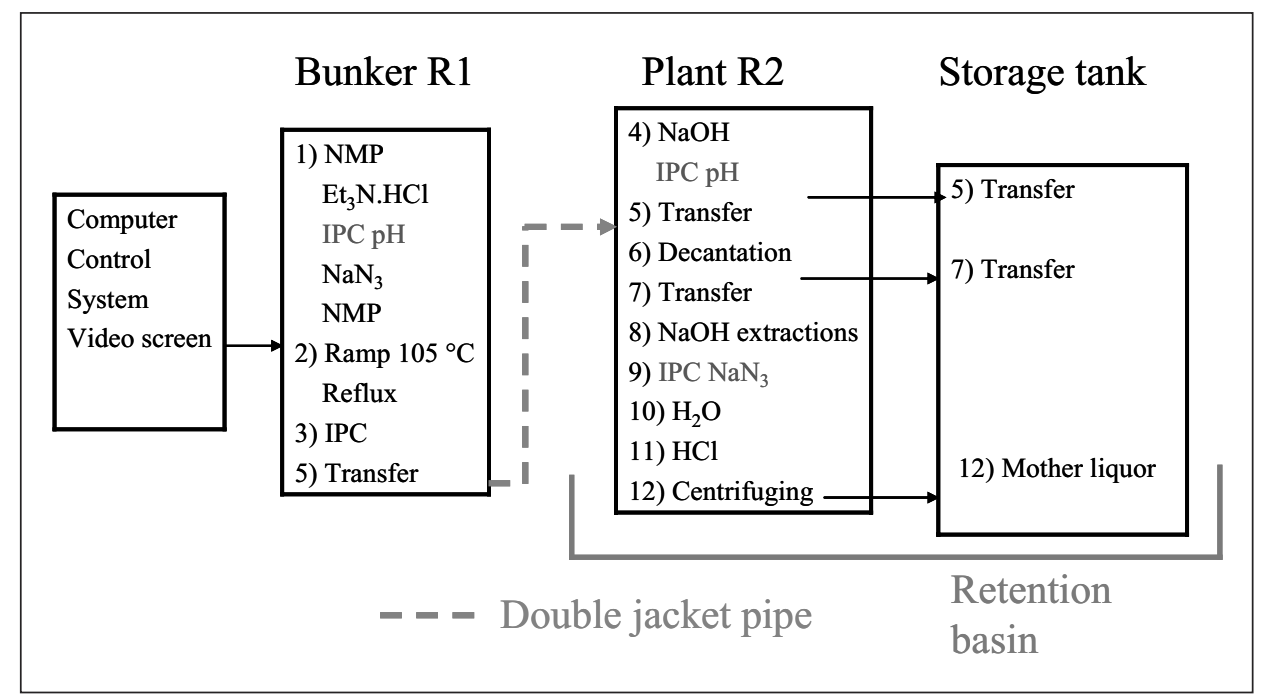

Fig. 1. Flux diagram 


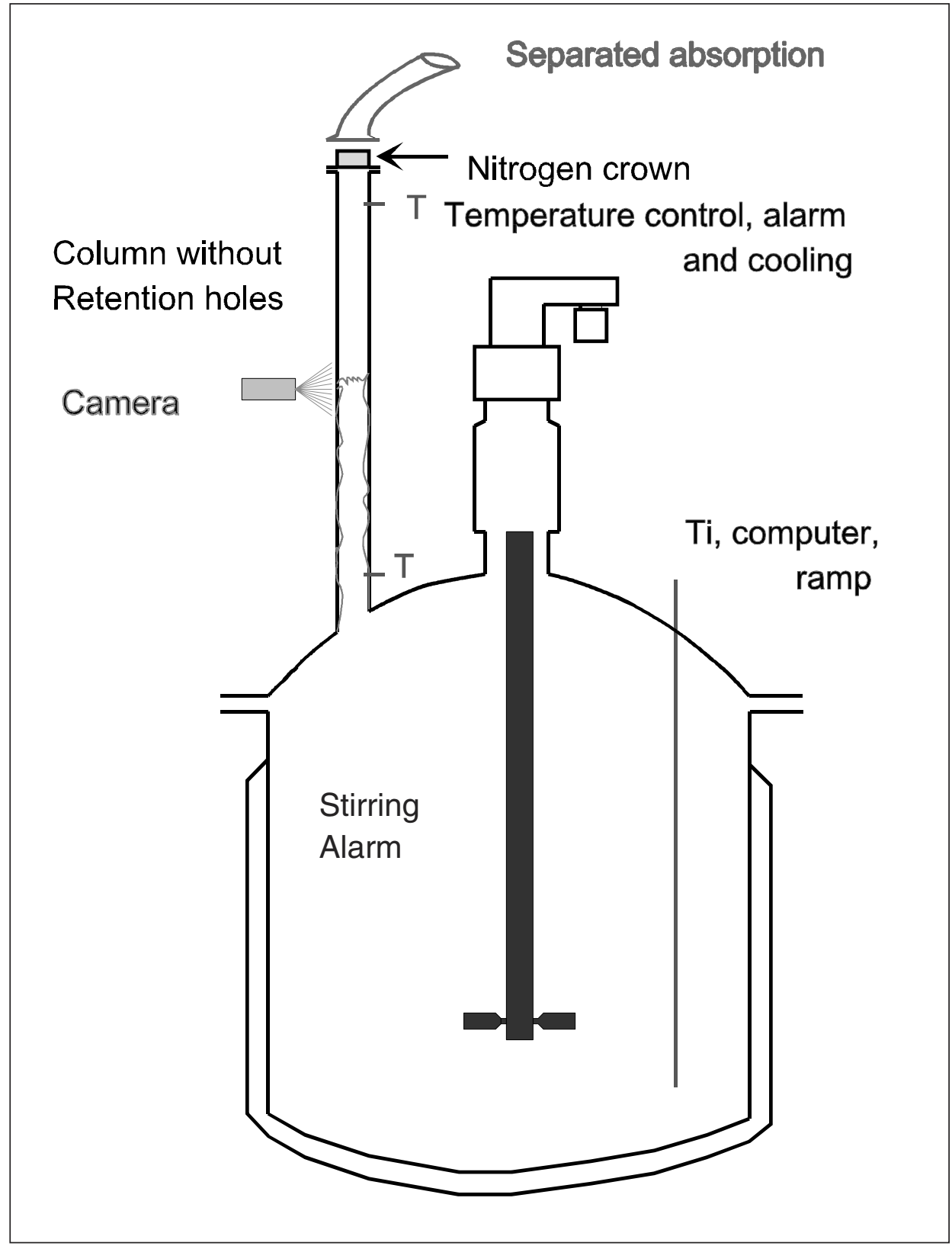

Fig. 2. Reactor

\subsubsection{Organisational Measures}

The safety critical tests described above are monitored by using a checklist. At the beginning of a campaign, each employer is instructed concerning the process safety measures and signs that he understands them. The installation including the absorber is dismantled and thoroughly cleaned twice a year. At the same time the integrity of glass and coatings is tested. Periodically, internal audits evaluate whether the initial measures arising from the risk assessment are still correctly followed.

\subsection{Controversy}

The reaction takes place in DMF, which has a boiling point of $202{ }^{\circ} \mathrm{C}$. Why do we have a reflux at about $105{ }^{\circ} \mathrm{C}$ ? The answer is that the refluxing entity is triethylamine.
It is present in the gas phase of the reactor at a concentration $10^{4}$ to $10^{6}$ higher than that of the azide ion. Solid crystals are observed in the distillation column. They consist of triethyl ammonium azide, which is heat and shock stable, in contrast to ammonium azide.

In conclusion, the process is considered to be completely safe, which leads to the subsequent question: why build a bunker? The answer is that, with azides, remote risks are still present and one should never ignore them.

\subsection{Conclusion}

Azides are versatile intermediates for many organic synthesis routes. In industry they are used in large scale yielding many new important drugs and active products.
However, strict reaction conditions and security measures have to be followed to assure safety.

In our case, the process is quite safe due to the use of triethylamine. Looking for such compounds could be an interesting but still dangerous research project.

Received: October 3, 2003

[1] S.G. Alvarez, M.T. Alvarez, Synthesis 1997, 413.

[2] K. Turnbull, Chem. Rev. 1988, 88, 297.

[3] P.T. Nyffeler, C.-H. Liang, K.M. Koeller, C.-H. Wong, J. Am. Chem. Soc. 2002, 124, 10773.

[4] G.A. Olah, T.D. Ernst, J. Org. Chem. 1989, 54, 1203

[5] D.A. Evans, T.C. Britton, J. Am. Chem. Soc. 1987, 109, 6881 .

[6] D.V. Banthorpe in, 'The Chemistry of the Azido Group', Ed. S. Patai, Wiley: NY, 1971, 397.

[7] M.T. Reagen, A.J. Nickon, J. Am Chem. Soc. 1968, 90, 4096; Y. Lee, W.D. Closson, Tetradron Lett. 1974, 381.

[8] O.C. Dermer, G.E. Ham, 'Ethylenimine and Other Aziridines', Academic Press: NY, 1969, 68.

[9] A. Kumar, R. Narayanan, H. Shechter, J. Org. Chem. 1996, 61, 4462.

[10] S.J. Wittenberger, B.G. Donner, J. Org. Chem. 1993, 58, 4139.

[11] A. Caron, D. Chantreux, C. Bouloumie, Eur. Pat. Appl. EP 708,103, 1996; P.R. Bernstein, E.P. Vacek, Synthesis 1987, 1133; W.G. Finnegan, R.A. Henry, R. Lofquist, J. Am. Chem. Soc. 1958, 80, 3908.

[12] Z.P. Demko, K.B. Sharpless, J. Org. Chem. 2001, 66, 7945.

[13] A.M.P. Koskinen, L. Munoz, J. Chem. Soc., Chem. Commun. 1990, 652.

[14] A. Subbaraj, O. Rao, W. Lwowski, J. Org. Chem. 1989, 54, 3945.

[15] E.A. Betterton, Science News 2000, 147, 251.

[16] E. Van Wambeke, D. Van den Abeele, Acta Hort. (ISHS) 1984, 152, 147.

[17] A. Yanagi, Pflanzenschutz-Nachrichten Bayer 2001, 54, 1.

[18] F. Janssens, J. Torremans, P.A.J. Janssen, J. Med. Chem. 1983, 29, 2290.

[19] R.D. Larsen, A.O. King, C.H.Y. Chen, E.G. Corley, B.S. Foster, F.E. Roberts, C. Yang, D.R. Lieberman, R.A. Reamer, D.M. Tschaen, T.R. Verhoeven, P.J. Reider, J. Org. Chem. 1994, 59, 6391.

[20] A. Caron, D. Chantreux, C. Bouloumie, Eur. Pat. EP 0708103 A1, 1996.

[21] T. Brossette, A.L. Faou, L. Goujon, A. Valleix, C. Créminon, J. Grassi, C. Mioskowskim L. Lebeau, J. Org. Chem. 1999, 64, 5083.

[22] R. Pellerin, ICI Explosifs Inc., Fiche 55.

[23] N.P. Peet, P.M. Weintraub, Chem. Ing. News 1994, 72, 4. 